\title{
Monitoring Ag-Cr Interactions in SOFC Cathodes Using Raman Spectroscopy
}

\author{
Harry W. Abernathy, ${ }^{* \dagger}$ Erik Koep, ${ }^{\ddagger}$ Charles Compson, ${ }^{\S}$ Zhe Cheng, ${ }^{\dagger}$ and Meilin Liu ${ }^{\dagger}$ \\ School of Materials Science and Engineering, Georgia Institute of Technology, 771 Ferst Drive NW, \\ Atlanta, Georgia 30332
}

Received: October 27, 2007; Revised Manuscript Received: June 11, 2008

\begin{abstract}
Due to its excellent conductivity and catalytic activity toward oxygen reduction, silver has been used as cathode (or electrocatalyst), current collector, or electrical contact in low-temperature solid oxide fuel cells (SOFCs). Here we report our findings on the contamination of silver or a silver-containing cathode from the chromium oxide layer found on a Cr-containing interconnect. Silver wire was attached to a patterned $\mathrm{La}_{0.8} \mathrm{Sr}_{0.2} \mathrm{MnO}_{3}$ cathode deposited onto a yttrium oxide-stabilized zirconium oxide substrate. The samples were placed inside a temperature- and atmosphere-controlled sample chamber filled with Cr-containing vapor. Raman spectra collected in situ from the sample surface revealed the formation of silver chromate, $\mathrm{Ag}_{2} \mathrm{CrO}_{4}$, on the silver surface at temperatures as low as $500{ }^{\circ} \mathrm{C}$. At $625^{\circ} \mathrm{C}$, the $\mathrm{Ag}_{2} \mathrm{CrO}_{4}$ was found to have vaporized and deposited across the LSM surface. In light of this contamination, special attention should be given to the selection of a metallic interconnect layer for an SOFC system that uses silver or a silver-containing cathode. Further, the use of in situ Raman spectroscopy as a powerful tool for probing and mapping new phase formation on electrode surfaces under fuel cell operating conditions is demonstrated.
\end{abstract}

\section{Introduction}

Solid oxide fuel cells (SOFCs) are an attractive alternative power generation source due to their higher fuel efficiencies and cleaner emissions compared to traditional fossil fuel combustion systems. ${ }^{1}$ Despite their performance advantages, SOFCs are not yet commercially viable due to high system costs. Not the cost of electrode and electrolyte materials per se, but rather for the interconnect materials and other balance-of-plant components, which must be exotic ceramics due to stability and thermal expansion requirements for operating the system at such high temperatures. ${ }^{2,3}$ Less expensive components, such as stainless steel interconnects, can be used if the SOFC is operated below $700{ }^{\circ} \mathrm{C}$ temperature. ${ }^{4,5}$ However, the cell performance decreases rapidly as the operating temperature is reduced because the conductivity and catalytic activity of the oxide phases decrease.

Conductivity losses in the electrolyte have been overcome by choosing different electrolyte materials and/or by making the electrolyte layer thinner. ${ }^{6-9}$ With an electrolyte better suited for lower operating temperatures, the cell performance becomes limited by the interfacial polarization resistance between the cathode and the electrolyte. ${ }^{10}$ To improve cathode performance, alternative cathode materials are being pursued to increase the cathode's catalytic activity toward oxygen reduction within this "intermediate temperature" range. The guiding strategy for this goal has been to incorporate mixed ionic/electronic conduction into the cathode, extending the oxygen reduction reaction beyond the triple phase boundary (TPB) between the gas, cathode, and electrolyte phases to include the entire gas/cathode interface.

Single mixed-conducting phases have been studied, including Ba-, Sr-, and La-based perovskites, ${ }^{11} \mathrm{Ru}$-based pyrochlores, ${ }^{12,13}$ and $\mathrm{K}_{2} \mathrm{NiF}_{4}$-type oxides. ${ }^{14,15}$ Alternatively, two-phase cathodes

* To whom correspondence should be addressed. E-mail: Harry.Abernathy@ gatech.edu. Tel: +1-404-519-1406.

$\dagger$ Georgia Institute of Technology.

¥Departament d'Electrónica, Universitat De Barcelona.

$\S$ Almatis Incorporated, Pittsburgh, PA. have been studied that use a strictly ionic or mixed conducting oxide phase coupled with a noble metal such as Pd, Pt, or Ag. ${ }^{16}$ The noble metal phase boosts the electronic conductivity of the cathode while still providing a surface that is active toward oxygen reduction. As cost is the driving force to lowering the SOFC operating temperature, silver is the preferred candidate among the noble metals. Silver had been previously disregarded as a cathode material due to its low melting point $\left(962{ }^{\circ} \mathrm{C}\right.$ ), making it susceptible to vaporization at the higher operating temperatures of conventional SOFC systems, ${ }^{17}$ but it once again becomes viable in a lower temperature range. So far, the addition of silver to SOFC cathodes has generated mixed results. Haanapel, et al., reported that the sintering temperature restrictions imposed by silver lessens the performance of a cell compared to that of an optimized Ag-free cell. ${ }^{16}$ Also, Camaratta, et al., observed unstable performances in their Ag- and bismuth oxide-based cathodes due to silver grain growth under operating conditions. ${ }^{18}$ In contrast, many groups have measured an improved cathode performance with the addition of small amounts of silver. ${ }^{19-24}$ In addition, silver is often used as a current collector (mesh or paste), electrical contact (paste), or lead wire when measuring the electrochemical performance of low-temperature SOFC samples.

The previous studies on the addition of silver to the cathode (or studies that used Ag elsewhere within an SOFC) only involved single cell tests. Again, one must remember the reason for the low-temperature SOFC is to reduce system costs, partially by replacing expensive oxide interconnect layers with metal ones. Most of these replacement alloys, such as the stainless steels, contain chromium. The use of stainless steel has raised concerns because the chromium has been found to leave the steel through the $\mathrm{Cr}_{2} \mathrm{O}_{3}$ surface layer on the steel and to contaminate some cathode materials. ${ }^{25}$ For example, phases such as $\mathrm{Cr}_{2} \mathrm{O}_{3}, \mathrm{SrCrO}_{4}$ and $(\mathrm{Mn} / \mathrm{Cr})_{3} \mathrm{O}_{4}$ have been found within cathodes operated in contact with various $\mathrm{Cr}$-containing alloys. $^{26-28}$ These contaminants slowly degrade cell performance, blocking conduction pathways through the cathode and 


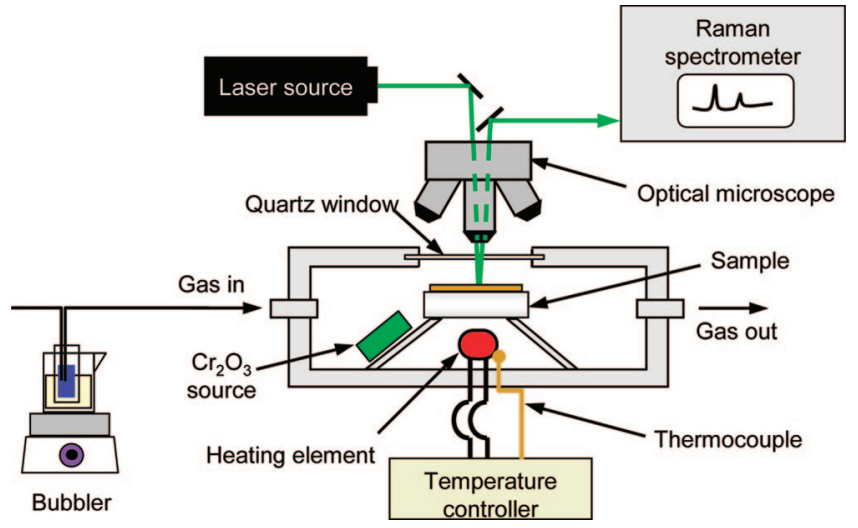

Figure 1. Schematic of the experimental setup for the Raman investigation of interaction between $\mathrm{Cr}$ vapor and silver-containing cathode.

reducing the amount of active cathode surface. Since silver can react with $\mathrm{Cr}_{2} \mathrm{O}_{3}$ to form phases such as $\mathrm{Ag}_{2} \mathrm{CrO}_{4}$ and $\mathrm{AgCrO}_{2},{ }^{29}$ the possibility exists for the contamination of the silver phase by chromium from a metallic interconnect. The work reported here explores this possibility by exposing silver and a $\mathrm{La}_{0.8} \mathrm{Sr}_{0.2} \mathrm{MnO}_{3}$ cathode to $\mathrm{Cr}$-containing vapor between 500 and $700{ }^{\circ} \mathrm{C}$. We used Raman spectroscopy to monitor in situ the formation of any $\mathrm{Ag}-\mathrm{Cr}$ phases.

\section{Experimental Methods}

The experimental setup for all Raman experiments is shown in Figure 1. The experiments were carried out in a temperatureand atmosphere-controlled reaction chamber covered with a quartz window (special order, Harrick Scientific). To generate Cr-containing vapor, two small pellets of $\mathrm{Cr}_{2} \mathrm{O}_{3}$ powder (Aldrich) were affixed, using gold paste, to the side of the sample cup facing the gas inlet. The inlet air was humidified by directing it through a bubbler sitting in an oil bath kept at $90{ }^{\circ} \mathrm{C}$. The inlet and outlet lines to the chamber were wrapped in heating tape (also maintained at $90{ }^{\circ} \mathrm{C}$ ) to prevent condensation. The air was humidified to promote the formation of $\mathrm{Cr}$-containing vapor phases such as $\mathrm{CrOOH}$ and $\mathrm{CrO}_{2}(\mathrm{OH})_{2}$. All Raman spectra were recorded using a Renishaw RM 1000 Raman microscope through a 50X objective lens using a $25 \mathrm{~mW} 514$ $\mathrm{nm}$ argon ion laser source (Melles Griot). Positioning was controlled on the micron-scale by a motorized $x-y-z$ stage (Prior Scientific).

Two sets of experiments were performed to measure the effect of Cr-containing vapor on a silver-containing SOFC. The first experiment was designed to confirm the generation of $\mathrm{Cr}$ containing vapor and to confirm a reaction between the vapor and silver metal. For this, a piece of silver mesh was placed on top of a pellet of gadolinium oxide-doped cerium oxide (GDC), a candidate SOFC electrolyte material. The pellet was then placed upon the sample cup inside the sample chamber. The GDC pellet acted as a buffer between the silver mesh and the stainless steel sample cup. We prevented direct contact between the silver and stainless steel to eliminate the possibility of a solid state reaction between the oxide layer on the stainless steel and the wire. Any chromium contamination observed on the mesh would thus result from reaction with $\mathrm{Cr}$-containing vapor. The sample was heated at $6{ }^{\circ} \mathrm{C} / \mathrm{min}$ to $500{ }^{\circ} \mathrm{C}$. The sample temperature was held every $50{ }^{\circ} \mathrm{C}$ to collect Raman spectra from various locations on the silver surface.

The second type of experiment tested for interactions between the $\mathrm{Cr}$-containing vapor and an SOFC cathode that contained
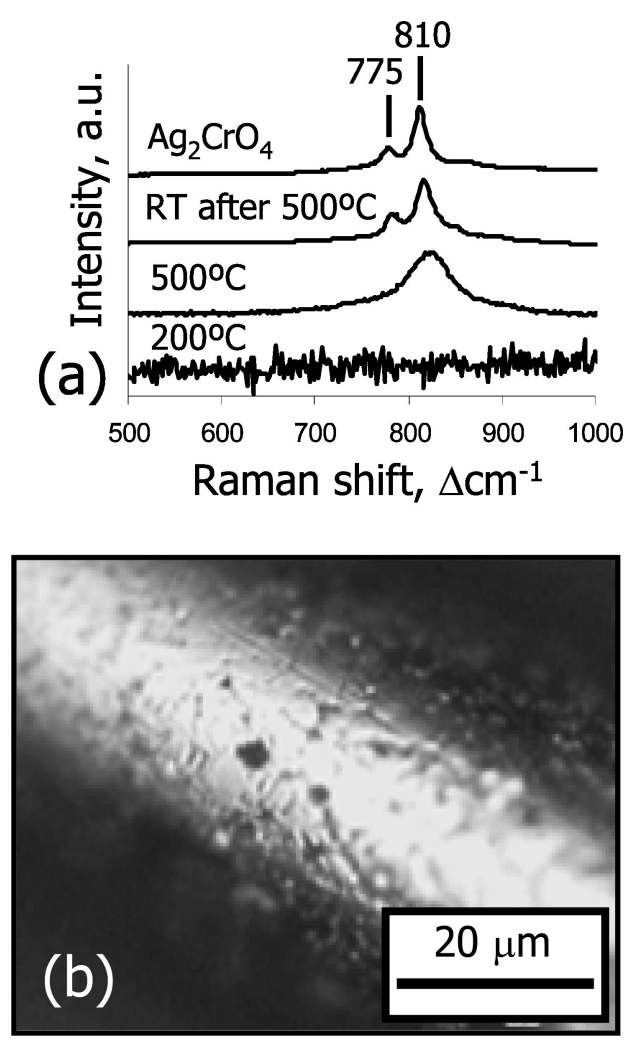

Figure 2. (a) Raman spectra from silver mesh exposed to Cr-containing vapor at different temperatures compared to that of $\mathrm{Ag}_{2} \mathrm{CrO}_{4}$ powder. (b) Optical micrograph of red deposit on silver mesh from which the room temperature spectrum in (a) after cooling from $500{ }^{\circ} \mathrm{C}$.

silver. The sample was a dense yttrium oxide-stabilized zirconium oxide (YSZ) pellet onto which a micropatterned $\mathrm{La}_{0.8} \mathrm{Sr}_{0.2} \mathrm{MnO}_{3}$ (LSM) electrode had been deposited using standard microelectronic fabrication methods. ${ }^{30}$ The LSM electrode contained $50 \mu \mathrm{m}$-wide LSM strips separated by 50 $\mu \mathrm{m}$ gaps. A platinum current collector composed of $50 \mu \mathrm{m}$ wide Pt strips had been deposited on top of the LSM, but the current collector was not utilized in this experiment, as no current was passed through the cell. To incorporate silver into the sample, a silver wire was attached to one side of the patterned LSM electrode using silver paste. The sample, with silver wire attached, was placed on the sample cup and heated inside the Raman sample chamber to $625^{\circ} \mathrm{C}$ in dry air. Once at temperature, the dry air was directed through the bubbler to expose the sample and chromium source to humidified air. Raman spectra were collected from the silver wire, the LSM electrode, and the exposed YSZ surface as a function of time at $625^{\circ} \mathrm{C}$. After three weeks exposure, the sample was cooled to room temperature and examined using Raman spectroscopy and SEM/EDS (Hitachi S800).

\section{Results and Discussion}

Figure 2a contains typical Raman spectra collected at different temperatures from the surface of the silver mesh exposed to Cr-containing humidified air. Raman spectra were collected in $50{ }^{\circ} \mathrm{C}$ intervals after $30 \mathrm{~min}$ at the desired temperature, with no anomalous Raman signals detected until the mesh reached $500{ }^{\circ} \mathrm{C}$. At this temperature, a broad peak centered at $820 \mathrm{~cm}^{-1}$ was observed at certain points on the mesh. The sample was then cooled at approximately $6{ }^{\circ} \mathrm{C} / \mathrm{min}$ to room temperature so that the chamber could be opened and the sample surface could be observed more clearly. Small brownish-red particles, the dark 
particles shown on the Ag surface in Figure 2b, had developed on the silver surface. The color matches that of silver chromate, $\mathrm{Ag}_{2} \mathrm{CrO}_{4}{ }^{31}$ The peaks in the Raman spectrum in Figure $2 \mathrm{a}$ from one of the particles also match those of orthorhombic $\mathrm{Ag}_{2} \mathrm{CrO}_{4}$ reported by Clark and Dines. ${ }^{32}$ The reference spectrum shown in Figure $2 \mathrm{a}$ was collected at room temperature from $\mathrm{Ag}_{2} \mathrm{CrO}_{4}$ powder purchased from Alfa Aesar. The family of peaks centered around $810 \mathrm{~cm}^{-1}$ from the room temperature spectra shift broaden and merge together with increasing temperature, resulting in the single broad feature observed in the in situ spectrum collected at $500{ }^{\circ} \mathrm{C}$. This effect was confirmed by measuring the Raman spectrum of a pressed $\mathrm{Ag}_{2} \mathrm{CrO}_{4}$ powder compact as a function of temperature within the Raman sample chamber.

Abu-Zied observed the formation $\mathrm{Ag}_{2} \mathrm{CrO}_{4}$ at $300{ }^{\circ} \mathrm{C}$ when reacting $\mathrm{Cr}_{2} \mathrm{O}_{3}$ and $\mathrm{AgNO}_{3}$ in air through a $\mathrm{CrOOH}$ intermediate. ${ }^{29}$ Our Raman measurements did not detect the presence of $\mathrm{Ag}_{2} \mathrm{CrO}_{4}$ until $500{ }^{\circ} \mathrm{C}$. This discrepancy can be explained by the higher reactivity of $\mathrm{AgNO}_{3}$, which decomposes at $500{ }^{\circ} \mathrm{C}$, and by the more intimate contact between the $\mathrm{Cr}$ and $\mathrm{Ag}$ sources in Abu-Zied's experiments. Our experiment relied upon a gas-solid interaction, and the vapor pressures of chromia and chromium oxyhydroxides are low below $800^{\circ} \mathrm{C} .{ }^{33}$ Also, during heating, our sample was only held for $30 \mathrm{~min}$ at each temperature before collecting a Raman spectrum. Longer exposure times at lower temperatures may result in detection of $\mathrm{Ag}_{2} \mathrm{CrO}_{4}$ formation at these temperatures. As the objective of this study was to mimic intermediate temperature SOFC operating conditions, the presence of $\mathrm{Ag}_{2} \mathrm{CrO}_{4}$ at $500{ }^{\circ} \mathrm{C}$, the lower end of intermediate temperature range, is significant.

Instead of a reaction between silver and $\mathrm{CrOOH}$, the authors believe the silver chromate was formed primarily through a reaction with $\mathrm{CrO}_{2}(\mathrm{OH})_{2}$ :

$$
1 /{ }_{2} \mathrm{O}_{2}+\mathrm{CrO}_{2}(\mathrm{OH})_{2}+2 \mathrm{Ag} \rightarrow \mathrm{Ag}_{2} \mathrm{CrO}_{4}+\mathrm{H}_{2} \mathrm{O}
$$

This chromium oxyhydroxide species is proposed since it has the highest partial pressure (in the temperature range studied) of the expected $\mathrm{Cr}-\mathrm{O}-\mathrm{H}$ compounds formed when $\mathrm{Cr}_{2} \mathrm{O}_{3}$ is exposed to a humidified oxidizing environment. ${ }^{34}$

If an SOFC stack utilizing stainless steel interconnects were operated at $500{ }^{\circ} \mathrm{C}$, any exposed silver in the cathode could have its surface contaminated with $\mathrm{Ag}_{2} \mathrm{CrO}_{4}$. Since $\mathrm{Ag}_{2} \mathrm{CrO}_{4}$ is conductive at this temperature, its formation does not interfere significantly with the use of $\mathrm{Ag}$ as an electronically conductive phase in the cathode. What may be impacted is the catalytic activity of the Ag toward oxygen reduction, which is lowered as the $\mathrm{Ag}$ surface converts to $\mathrm{Ag}_{2} \mathrm{CrO}_{4}$. Of greater concern is the melting point of $\mathrm{Ag}_{2} \mathrm{CrO}_{4}, 658{ }^{\circ} \mathrm{C} .{ }^{35}$ Its melting point is lower than that of silver, $962{ }^{\circ} \mathrm{C}$, meaning that within normal SOFC operating temperatures, the $\mathrm{Ag}_{2} \mathrm{CrO}_{4}$ could melt or volatilize. The continual loss of $\mathrm{Ag}_{2} \mathrm{CrO}_{4}$ to vaporization would eventually weaken the contact between the silver phase, the interconnect, and the other cathode phase. It may also contaminate other parts of the cell through condensation or chemical reaction.

The effect of the vaporization of $\mathrm{Ag}_{2} \mathrm{CrO}_{4}$ was observed in the experiments involving the micropatterned LSM cathode samples with attached silver wire. Figure 3 contains Raman spectra collected in situ at $625^{\circ} \mathrm{C}$ from a patterned LSM sample exposed to $\mathrm{Cr}$-containing vapor. Within $36 \mathrm{~h}$, the signal from $\mathrm{Ag}_{2} \mathrm{CrO}_{4}$ on the silver wire was very intense. The slight shoulder at $875 \mathrm{~cm}^{-1}$, which was not detected on the $\mathrm{Ag}$ wire when heated without $\mathrm{LSM}$ present, was attributed to $\mathrm{SrCrO}_{4}$. At room temperature, $\mathrm{SrCrO}_{4}$ exhibits two intense Raman peaks at 863

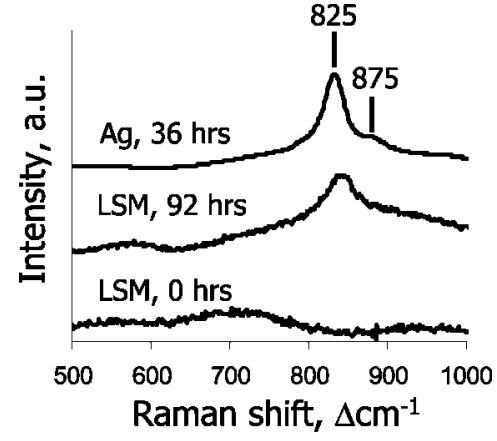

Figure 3. Raman spectra from micropatterned LSM electrodes on YSZ substrate collected in situ at $625{ }^{\circ} \mathrm{C}$ during exposure to $\mathrm{Cr}$ vapor. The LSM spectra were measured on surfaces close to where the Ag wire was attached to the sample.

and $890 \mathrm{~cm}^{-1} .36$ These two peaks probably broaden and merge together at higher temperatures (similar to the observed effect with $\mathrm{Ag}_{2} \mathrm{CrO}_{4}$ ), creating the $875 \mathrm{~cm}^{-1}$ peak seen from our sample. Within four days exposure, reddish-brown $\mathrm{Ag}_{2} \mathrm{CrO}_{4}$ crystals, which we could observe visually on the $\mathrm{Ag}$ wire, began to form on the LSM electrode to which the Ag wire was attached. The Raman spectrum from the LSM revealed a broad peak centered at $830 \mathrm{~cm}^{-1}$. We believe the $\mathrm{Ag}_{2} \mathrm{CrO}_{4}$ deposited on the LSM through vaporization and condensation. The shift in the peak position could result from a defective structure caused by the deposition of the $\mathrm{Ag}_{2} \mathrm{CrO}_{4}$ onto the LSM perovskite surface.

Further evidence of $\mathrm{Ag}_{2} \mathrm{CrO}_{4}$ vaporization is shown in the optical micrograph in Figure 4a taken at room temperature after exposure to $\mathrm{Cr}$ vapor at $625^{\circ} \mathrm{C}$ for 3 weeks. A room temperature micrograph obtained after cooling is shown here because the in situ images taken were blurry due to the sample temperature and to the quartz window between the objective and the sample. In the image, the silver wire crosses the upper left corner while the platinum current collector runs across the upper right corner. The lighter regions are the YSZ substrate. The red $\mathrm{Ag}_{2} \mathrm{CrO}_{4}$ phase can be seen visually on the LSM, but not on the YSZ regions between the LSM strips.

A Raman map of the $\mathrm{Ag}_{2} \mathrm{CrO}_{4}$ phase was generated by collecting a Raman spectrum every $10 \mu \mathrm{m}$ within the $200 \mu \mathrm{m}$ $\times 280 \mu \mathrm{m}$ grid detailed in Figure 4a. To create the map shown in Figure $4 \mathrm{~b}$, the integrated peak intensity of the $810 \mathrm{~cm}^{-1}$ $\mathrm{Ag}_{2} \mathrm{CrO}_{4}$ peak was calculated from each spectrum and plotted as a function of position. In the map, a lighter color indicates a higher peak intensity. The presence of the $810 \mathrm{~cm}^{-1}$ peak correlates with the presence of the red deposit on the LSM. The sample was further examined ex situ using SEM. The SEM image in Figure 5a shows the morphology of the LSM surface. The corresponding silver EDS map in Figure 5b confirms the existence of a Ag-containing phase on the electrode surface.

The lack of any appreciable $\mathrm{Ag}_{2} \mathrm{CrO}_{4}$ signal on the YSZ surface eliminates the possibility of a surface diffusion mechanism, as some $\mathrm{Ag}_{2} \mathrm{CrO}_{4}$ would have been trapped on the YSZ during the quenching of the sample to room temperature. Instead, the $\mathrm{Ag}_{2} \mathrm{CrO}_{4}$ vaporized from the $\mathrm{Ag}$ wire surface and deposited preferentially on the LSM. We cannot definitively explain the affinity between $\mathrm{Ag}_{2} \mathrm{CrO}_{4}$ and LSM besides conjecturing that the positive driving force for $\mathrm{SrCrO}_{4}$ formation (or some mixed $\mathrm{Ag}_{2} \mathrm{CrO}_{4}-\mathrm{SrCrO}_{4}$ phase) may promote the adsorption of $\mathrm{Ag}_{2} \mathrm{CrO}_{4}$ to the LSM surface. To test this hypothesis, a similar experiment could be performed with a cathode material that does not contain a cation species such as strontium (or manganese) that reacts with chromium. 

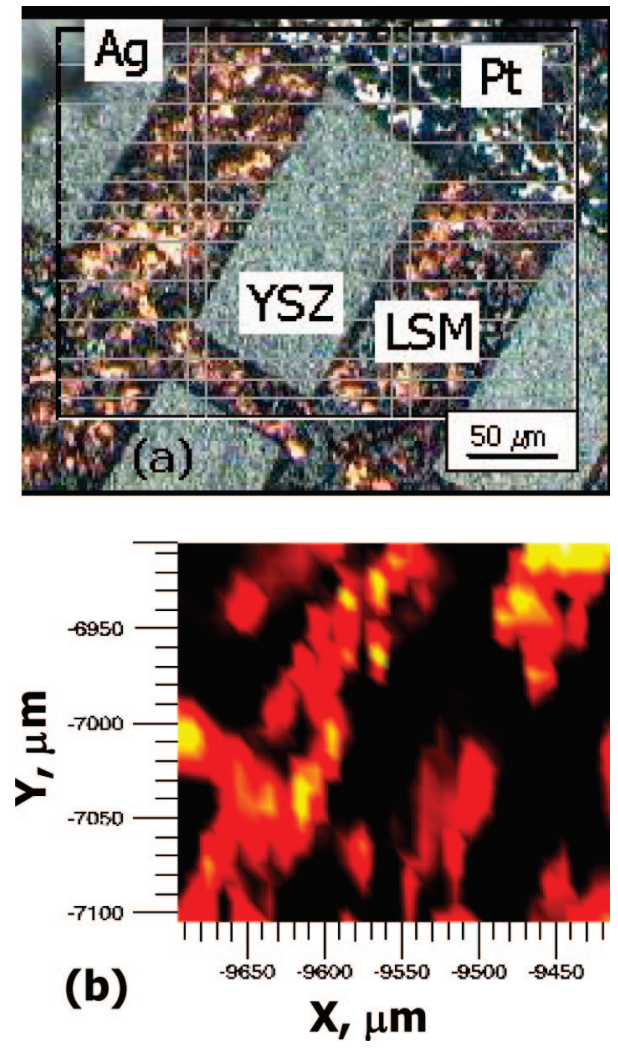

Figure 4. (a) Optical micrograph detailing area on patterned LSM sample to collect Raman map (b) plotting the integrated intensity of the $810 \mathrm{~cm}^{-1}$ Raman peak. The lighter regions are YSZ, the crosshatched electrode is LSM, and the strip across the upper right corner is platinum. The Ag wire can be seen in the upper left corner.

The deposition of $\mathrm{Ag}_{2} \mathrm{CrO}_{4}$ on LSM is significant since it eliminates active LSM surface area that could be used for oxygen reduction. For the sample shown in Figure 4, $\mathrm{Ag}_{2} \mathrm{CrO}_{4}$ was detected up to $500 \mu \mathrm{m}$ away from the silver source after the 3 weeks of exposure to Cr vapor. For SOFCs with stainless steel interconnects and cathodes containing a mixture of silver and another phase, $\mathrm{Ag}_{2} \mathrm{CrO}_{4}$ can quickly cover the surrounding surfaces throughout the entire cathode. Even if a layer of silver is used in an SOFC stack as a buffer layer between the interconnect and the cathode (in principle, to help prevent $\mathrm{Cr}$ contamination of the cathode), $\mathrm{Ag}_{2} \mathrm{CrO}_{4}$ vapor could still permeate throughout most of the cathode within $1000 \mathrm{~h}$ of operation, as most cathodes are between 10 and $100 \mu \mathrm{m}$ thick.

Both sets of experiments detailed here involved chemical exposure of silver and an SOFC cathode to $\mathrm{Cr}$ vapor. While the temperature and atmospheric conditions of an intermediate temperature SOFC were duplicated in our sample chamber, the sample was not polarized electrically to observe electrochemical exposure. This is a significant point to consider, as the bias applied across the cell could promote the reduction of the $\mathrm{Ag}^{1+}$ or $\mathrm{Cr}^{6+}$ within $\mathrm{Ag}_{2} \mathrm{CrO}_{4}$. Silver chromate has been shown to reduce in aqueous solutions at room temperature, forming metallic silver and aqueous chromium oxide species. ${ }^{37,38}$ The possibility thus exists that polarizing the cell may stabilize the metallic silver; however, the chromium could either remain in the vapor phase or reduce from $\mathrm{Cr}^{6+}$ to $\mathrm{Cr}^{3+}$, forming a $\mathrm{Cr}_{2} \mathrm{O}_{3}$ scale on the silver surface. The formation of $\mathrm{Cr}_{2} \mathrm{O}_{3}$ is a possibility, since it is found as a $\mathrm{Cr}$ contaminant in SOFC cathodes that do not contain silver. If instead the chromium remains as a volatile $\mathrm{Cr}^{6+}$ species, this species could then still react with other phases in the cathode (e.g., LSM) to form
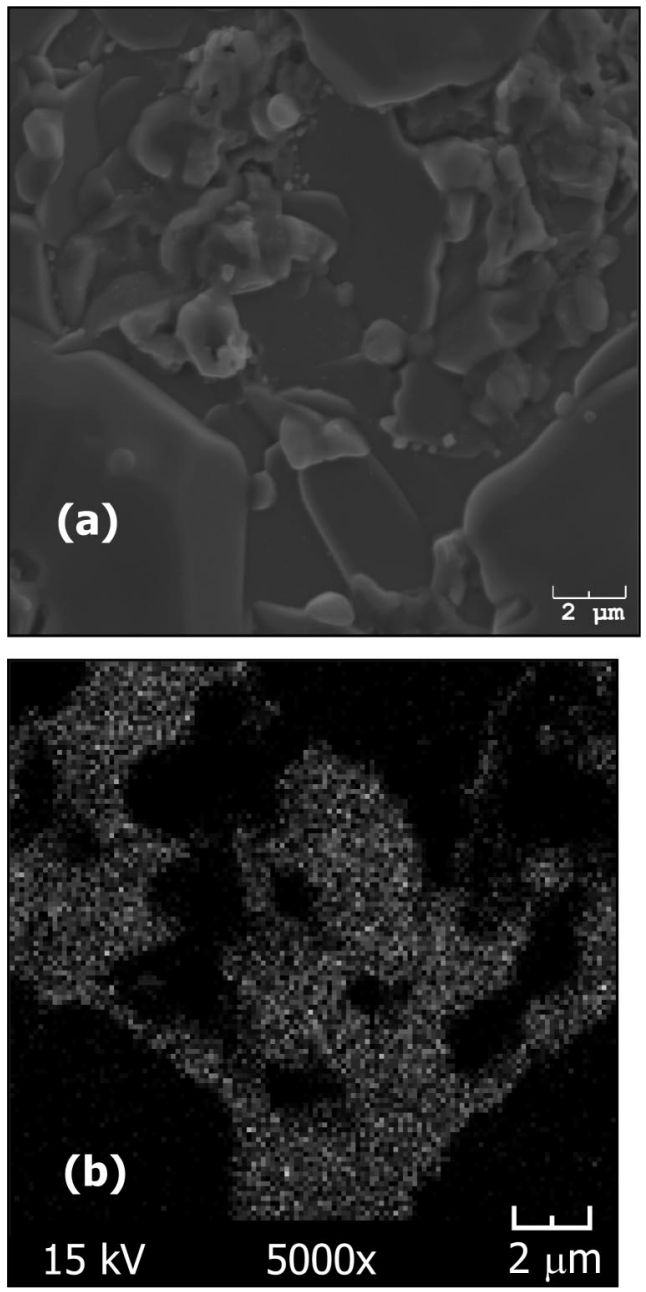

Figure 5. (a) SEM micrograph showing contaminated LSM surface. (b) EDS showing presence of silver from area shown in (a). The lighter areas indicate higher concentrations of $\mathrm{Ag}$.

$\mathrm{SrCrO}_{4}$ or the $(\mathrm{Mn} / \mathrm{Cr})_{3} \mathrm{O}_{4}$ spinel. Additional research thus needs to be done evaluating the stability of the $\mathrm{Ag}_{2} \mathrm{CrO}_{4}$ under polarized conditions. The chemical formation of $\mathrm{Ag}_{2} \mathrm{CrO}_{4}$ is still significant since it forms at such low temperatures that its presence will be felt before the cell reaches its operating temperature and a current is applied. Further, the formation of other $\mathrm{Cr}$ phases would only replace or add to the contamination caused by $\mathrm{Ag}_{2} \mathrm{CrO}_{4}$.

\section{Conclusions}

In this study, we used in situ Raman spectroscopy to monitor the contamination of a silver-containing SOFC cathode by volatile chromium species. Silver chromate, $\mathrm{Ag}_{2} \mathrm{CrO}_{4}$, was formed on the surface of silver wire exposed to $\mathrm{Cr}$-containing vapor at temperatures as low as $500{ }^{\circ} \mathrm{C}$. By $625^{\circ} \mathrm{C}$, the $\mathrm{Ag}_{2} \mathrm{CrO}_{4}$ was already vaporizing and depositing on the surface of an LSM electrode. The volatility of $\mathrm{Ag}_{2} \mathrm{CrO}_{4}$ under the operating conditions of an intermediate temperature SOFC would weaken the electrical contact between the silver and the rest of the cell, as well as reduce the catalytic activity of the cathode by covering its surface. In light of these effects, one should avoid using silver within an SOFC cathode in contact with an interconnect layer that forms a $\mathrm{Cr}_{2} \mathrm{O}_{3}$ layer on its surface, as with most stainless steels. The use of silver in a low-temperature SOFC must be in conjunction with an interconnect material that does not form a $\mathrm{Cr}_{2} \mathrm{O}_{3}$ surface layer. Alternatively, the volatility of the chromium 
could be inhibited by applying a thin film to the interconnect of a conductive material that does not react with chromium (or silver). Further research is still needed to test the electrochemical stability of $\mathrm{Ag}_{2} \mathrm{CrO}_{4}$ under fuel cell operating conditions, as it may reduce when a current is running through the cell. The experimental setup described in this work is capable of making in situ measurements while applying a potential across the sample. Of more general interest is how readily Raman microspectroscopy can be used to monitor the formation of new phases on a solid surface under in situ conditions. Not only can the phases be identified, but also their presence can be mapped as a function of time and position, making Raman spectroscopy an excellent in situ characterization method for catalysts and electrocatalysts.

Acknowledgment. This work was supported by the U.S. DOE-SECA Core Technology Program (Grant No. DE-FC2605NT42515), DOE Basic Energy Science (Grant No. DE-FG0206ER15837DOE), and an NSF Graduate Research Fellowship.

\section{References and Notes}

(1) Minh, N. Q.; Takahashi, T. Science and Technology of Ceramic Fuel Cells Elsevier Science, Amsterdam, 1995.

(2) Minh, N. Q. J. Am. Ceram. Soc. 1993, 76, 563.

(3) Choy, K.; Bai, W.; Charojrochkul, S.; Steele, B. C. H. J. Power Sources 1998, 71, 361 .

(4) Ormerod, R. M. Chem. Soc. Rev. 2003, 32, 17.

(5) Singh, P.; Minh, N. Q. Int. J. Appl. Ceram. Tech 2004, 1, 5.

(6) McEvoy, A. J. Solid State Ionics 2000, 132, 159.

(7) Gauckler, L. J.; Beckel, D.; Buergler, B. E.; Jud, E.; Muecke, U. R.; Prestat, M.; Rupp, J. L. M.; Richter, J. Chimia 2004, 58, 837.

(8) Ishihara, T.; Tabuchi, J.; Ishikawa, S.; Yan, J.; Enoki, M.; Matsumoto, H. Solid State Ionics 2006, 177, 1949.

(9) Huang, H.; Nakamura, M.; Su, P. C.; Fasching, R.; Saito, Y.; Prinz, F. B. J. Electrochem. Soc. 2007, 154, B20.

(10) Xia, C.; Rauch, W.; Chen, F.; Liu, M. Solid State Ionics 2002, $149,11$.

(11) Wincewicz, K. C.; Cooper, J. S. J. Power Sources 2005, 140, 280.

(12) Bae, J. M.; Steele, B. C. H. J. Electroceram. 1999, 3, 37.

(13) Zhong, Z. M. Electrochem. Solid State Lett. 2006, 9, A215.
(14) Kharton, V. V.; Tsipos, E. V.; Yaremchenko, A. A.; Frade, J. R. Solid State Ionics 2004, 166, 327.

(15) Aguadero, A.; Alonso, J. A.; Fenandez-Diaz, M. T.; Escudero, M. J.; Daza, L. J. Power Sources 2007, 169, 17.

(16) Haanappel, V. A. C.; Rutenbeck, D.; Mai, A.; Uhlenbruck, S.; Sebold, D.; Wesemeyer, H.; Rowekamp, B.; Tropartz, C.; Tietz, F. J. Power Sources 2004, 130, 119.

(17) Tedmon, C. S., Jr.; Spacil, H. S.; Mitoff, S. P. J. Electrochem. Soc. 1969, 116, 1170.

(18) Camaratta, M.; Wachsman, E. Solid State Ionics 2007, 178, 1242.

(19) Sasaki, K.; Hosoda, K.; Lan, T. N.; Yasumoto, K.; Wang, S.; Dokiya, M. Solid State Ionics 2004, 174, 97.

(20) Wang, S.; Kato, T.; Nagata, S.; Honga, T.; Kaneko, T.; Iwashita, N.; Dokiya, M. Solid State Ionics 2002, 146, 203.

(21) Wang, Y.; Wang, S.; Wang, Z.; Wen, T.; Wen, Z. J. Alloys Comp. 2007, 428, 286.

(22) Xia, C.; Zhang, Y.; Liu, M. Appl. Phys. Lett. 2003, 82, 901.

(23) Uhlenbruck, S.; Tietz, F.; Haanappel, V.; Sebold, D.; Buchkremer, H. P.; Stover, D. J. Solid State Electrochem. 2004, 8, 923.

(24) Lee, K. T.; Manthiram, A. J. Power Sources 2006, 160, 903.

(25) Hilpert, K.; Das, D.; Miller, M.; Peck, D. H.; Weiss, R. J. Electrochem. Soc. 1996, 143, 3642.

(26) Badwal, S. P. S.; Deller, R.; Foger, K.; Ramprakash, Y.; Zhang, J. P. Solid State Ionics 1997, 99, 297.

(27) Paulson, S. C.; Birss, V. I. J. Electrochem. Soc. 2004, 151, A1961.

(28) Jiang, S. P.; Zhang, S.; Zhen, Y. D. J. Electrochem. Soc. 2006, 153, A127.

(29) Abu-Zied, B. A. Appl. Catal., A 2000, 198, 139.

(30) Koep, E.; Compson, C.; Liu, M. L.; Zhou, Z. P. Solid State Ionics 2005, 176,1 .

(31) Robbins, D. J.; Day, P. Mol. Phys. 1977, 34, 893.

(32) Clark, R. J. H.; Dines, T. J. Inorg. Chem. 1982, 21, 3585.

(33) Tucker, M. C.; Kurokawa, H.; Jacobson, C. P.; DeJonghe, L. C.; Visco, S. J. J. Power Sources 2006, 160, 130.

(34) Opila, E. J.; Myers, D. L.; Jacobson, N. S.; Nielsen, I. M. B.; Johnson, D. F.; Olminsky, J. K.; Allendorf, M. D. J. Phys. Chem. A 2007, $111,1971$.

(35) Cieslak-Golonka, M. J. Therm. Anal. 1992, 38, 2501.

(36) Scheuermann, W.; Ritter, G. J.; Schutte, C. J. H. Z. Naturforsch. 1970, 25, 1856.

(37) Abd El Rehim, S. S.; Ibrahim, M. A. M.; Hassan, H. H.; Amin, M. A. Can. J. Chem. 1998, 76, 1156.

(38) Brunetti, V.; Villullas, H. M.; Lopez Teijelo, M. Electrochim. Acta 1999, 44, 2843.

JP804239T 